\title{
Probabilistic analysis of the strength and reliability of reinforced concrete structures under low-temperature impact
}

\author{
Boris Pinus ${ }^{1, *}$, and Zhanetta Pinus ${ }^{2}$ \\ 'Irkutsk National Research Technical University, 664074, Lermontova str., 83, Irkutsk, \\ Russia \\ ${ }^{2}$ Irkutsk State University of Communications, 664074, Chernyshevsky str., 15, Irkutsk, \\ Russia
}

\begin{abstract}
The paper presents the results of numerical modeling of the kinetics of strength and reliability of bent reinforced concrete elements in the process of cyclic low-temperature and humidity effects of various levels. In this case, the calculated strength model is adopted in accordance with the normative functional dependencies, taking into account the random nature of the implementation of the input parameters, while the reliability model is in the form of a safety factor determined by the statistical parameters of their distributions. The latter are taken on the basis of representative empirical data of changes in the strength and deformation of concrete and reinforcement (in concrete) at certain stages of depletion of the standard resource of frost resistance. Substantial differences are established in the change in the strength and reliability parameters for the FTC and the determining effect of the reinforcement level on their kinetics.
\end{abstract}

\section{Introduction}

Project security for the reliability of reinforced concrete structures for extreme operating conditions is achieved by adjusting the criterial equations of efficiency with a differentiated system of particular coefficients. It is assumed a priori monotonicity of the physical wear of the structure and ergodicity of external influences, which allows [1] to replace with an acceptable accuracy the real distribution of their random realizations to peak values. In a time aspect, such an approach means a hypothetical identity of the kinetics of exhaustion of the strength and reliability resource in the specific operating conditions.

Experimental and analytical verification of the validity of such a proposal for bent reinforced concrete elements, designed to work in harsh climatic conditions, is the objective of this study.

\footnotetext{
*Corresponding author: pinus@istu.edu
} 


\section{Materials and Methods}

Probabilistic prediction of the kinetics of strength and reliability is performed by numerical modeling using normative functional models and experimental statistically representative data on the change in the technical properties of concrete and reinforcement in the process of cyclic temperature-humidity influences (FTC). It is assumed that

- exhaustion of the resistance resource of the reinforced concrete element follows the principle of linear summation of destruction $[2,3]$, which allows to represent a continuous wear process in the form of temporary discrete implementations;

- the kinetics of exhaustion of the service life of the structure is identical to the change in the probability of parametric failures [4] in terms of the strength of normal sections;

- the time factor is taken into account in the form of an indicator of the relative level of exhaustion of frost resistance of concrete " $\mathrm{m}$ ", equal to the ratio of the actual number of FTCs to the frost resistance mark $(\mathrm{F})$.

With their use, the analysis of the dynamics of the performance of structures under lowtemperature influences is reduced to statistical generalizations of discrete probable strength and reliability values in correlation with the level of exhaustion of a standardized (and controlled) resource of frost resistance. The corresponding forecast of random realizations of strength is determined by a system of equations $[5,6]$ :

$$
\left\{\begin{array}{l}
\tilde{M}(m)=\widetilde{\alpha}_{m} \tilde{M}_{1}(m)+\left(1-\tilde{\alpha}_{m}\right) \tilde{M}_{2}(m) \\
\widetilde{M}_{1}(m)=\mu b h_{\mathrm{O}}^{2}[1-0,5 \tilde{\xi}(m)] \widetilde{\sigma}_{e} n p u \tilde{\xi}(m) \leq \widetilde{\xi}_{R}(m) \\
\tilde{M}_{2}(m)=b h_{\mathrm{O}}^{2} \widetilde{\xi}_{R}(m) \widetilde{R}_{b}(m)\left[1-0,5 \widetilde{\xi}_{R}(m)\right] n p u \tilde{\xi}(m)>\widetilde{\xi}_{R}(m)
\end{array},\right.
$$

where " $\sim$ " is the index denoting the random character of the parameter value; $\tilde{\alpha}_{m}=p\left[\tilde{\xi}(m)<\tilde{\xi}_{R}(m)\right]$ - the probability of destruction of the element due to reaching fluidity in the stretched rebars; $\tilde{\xi}(m), \tilde{\xi}_{R}(m)$ - respectively, the relative and boundary height of the compressed sectional area, determined by standard empirical relationships [7], taking into account the change in the strength, modulus, ultimate strains of concrete and reinforcement at the "m" level of impacts.

As a generalized indicator of reliability, the safety factor " $\gamma$ " is considered, which, on the proposal of A.P. Rzhanitsina [8] is determined by the following expression:

$$
\gamma_{m}=\frac{K_{1}(m)-1}{\sqrt{\sum C_{v_{i}}^{2}(m) K_{i}^{2}(m)+C_{v p}^{2}}},
$$

where $K_{1}(m)=\bar{M}(m) / M_{0}$ is the ratio of the calculated forces determined by the normative functional dependencies using the means (numerator) and the calculated (denominator) values of the parameters considered; $C_{v_{i}}(m), C_{v p}$ - respectively, are the coefficients of variability in the properties of materials and loads; $K_{i}(m)=\frac{\partial M(m)}{\partial X_{\mathrm{i}}} \tilde{X}_{i}(m)$ is the coefficients of the "weighted" participation of the $i$-th factor (parameter) in the analytical evaluation of the resistance value.

\section{Results}


As an experimental basis for numerical simulation, the results of statistically representative, purposeful low-temperature tests of conventional and reinforced prismatic concrete samples of class B30 and standard frost resistance F270 were used. Table 1 shows the average values and coefficients of variability of individual (sensitive to the FTC) indicators of the properties of concrete and the state of reinforcement, which are part of the analytical models for assessing the strength and reliability of structural reinforced concrete elements. Here also are the distribution statistics characterizing the dynamics of the boundary height of the compressed zone, estimated by the following expression:

$$
\xi_{R}(m)=\frac{\xi_{0}(m)}{1+\frac{\sigma_{e}-\Delta \varepsilon_{S}(m) E_{S}}{\varepsilon_{b}(m) E_{S}}\left(1-0,9 \xi_{0}(m)\right)}
$$

Table 1. Statistics of the distribution of controlled indicators of the quality of reinforced concrete elements (at the stages of thawing).

\begin{tabular}{|c|c|c|c|c|c|c|c|c|}
\hline \multirow[b]{2}{*}{$\begin{array}{l}\text { Level of } \\
\text { T-W } \\
\text { impact } \\
m\end{array}$} & \multicolumn{2}{|c|}{$\begin{array}{l}\text { Strength of } \\
\text { concrete }\end{array}$} & \multicolumn{2}{|c|}{ Limit deformaton } & \multicolumn{2}{|c|}{$\begin{array}{l}\text { Residual deformation } \\
\text { of rebars* }\end{array}$} & \multicolumn{2}{|c|}{$\begin{array}{l}\text { Boundary height of } \\
\text { the compressed zone }\end{array}$} \\
\hline & $\begin{array}{l}\text { Average } \\
\text { value, } \\
R_{b}(m) \\
(\mathrm{Mpa}) \\
\end{array}$ & $\begin{array}{l}\text { Coeffici } \\
\text { ent of } \\
\text { variation } \\
C_{v}(\%) \\
\end{array}$ & $\begin{array}{c}\text { Average } \\
\text { value, } \\
\varepsilon_{b}(m) \cdot 10\end{array}$ & \begin{tabular}{|c|}
$\begin{array}{c}\text { Coefficient } \\
\text { of } \\
\text { variation, } \\
C_{v}(\%)\end{array}$ \\
\end{tabular} & $\begin{array}{c}\text { Average } \\
\text { value, } \\
\Delta \varepsilon_{S}(m)\end{array}$ & $\begin{array}{c}\text { Coefficien } \\
\text { t of } \\
\text { variation, } \\
0^{-5} C_{v}(\%) \\
\end{array}$ & $\begin{array}{c}\text { Average } \\
\text { value, } \\
\xi_{R}(m)\end{array}$ & $\begin{array}{c}\text { Coeffici } \\
\text { ent of } \\
\text { variation } \\
C_{v}(\%) \\
\end{array}$ \\
\hline 0 & 24,0 & 12,5 & 16,9 & 11,6 & - & - & 0,442 & 6,8 \\
\hline 0,29 & 24,5 & 14,2 & 20,0 & 17,7 & 15,7 & 27,7 & 0,520 & 5,5 \\
\hline 0,86 & 20,2 & 27,0 & 33,4 & 28,1 & 29,1 & 28,9 & 0,561 & 7,3 \\
\hline 1 & 19,7 & 27,4 & 42,1 & 29,0 & 37,4 & 30,1 & 0,576 & 7,7 \\
\hline 1,29 & 19,1 & 27,6 & 65,7 & 31,9 & 51,5 & 31,7 & 0,600 & 8,6 \\
\hline
\end{tabular}

* According to strain gages with a base of $20 \mathrm{~mm}$, installed in the milled grooves of the reinforcing bars along the axis of the prisms $(100 \times 100 \times 400 \mathrm{~mm})$ in steps of $100 \mathrm{~mm}$.

Its expected values have a relatively high density and a slight asymmetry, which makes it possible to assume the stability of the approximating distributions in the considered range of temperature and humidity effects. In this case, a sequential increase with a dynamics that differs from the concrete strength indicates a gradual transformation of the deformation character [9], and, as a consequence, a change in the probability of the expected parametric failure. The results of numerical modeling and analysis of the joint distribution of calculated $\left(\xi_{i}(m)\right)$ and boundary $\left(\xi_{i_{R}}(m)\right)$ values (Table 2), performed for rectangular cross sections of bent elements, confirm this assumption.

Table 2. The probability of failure of an element due to achievement of rebars fluidity.

\begin{tabular}{|c|c|c|c|c|c|c|c|c|}
\hline \multirow{2}{*}{$\begin{array}{c}\text { Level T- } \\
\text { W } \\
\text { impact, } \\
m\end{array}$} & \multicolumn{6}{|c|}{ Value $\alpha_{m}$ with coefficient of reinforcement, $\mu(\%)$} & \multirow{2}{*}{$\begin{array}{c}\text { Boundary } \\
\text { reinforcement, } \\
\mu_{R}(\%)\end{array}$} \\
\hline 0 & 1,1 & 1,5 & 2,0 & 2,5 & 3,0 & 3,5 & 4,0 & 2,65 \\
\hline 0,29 & 1 & 1 & 1 & 0,885 & 0,612 & 0,421 & 0,175 & 3,06 \\
\hline 0,86 & 1 & $\begin{array}{c}0,98 \\
4\end{array}$ & 0,750 & 0,588 & 0,423 & 0,343 & 0,174 & 2,79 \\
\hline 1 & 1 & $\begin{array}{c}0,97 \\
9\end{array}$ & 0,747 & 0,562 & 0,427 & 0,364 & 0,169 & 2,82 \\
\hline
\end{tabular}




\begin{tabular}{|c|c|c|c|c|c|c|c|c|}
\hline 1,29 & 1 & $\begin{array}{c}0,97 \\
9\end{array}$ & 0,750 & 0,503 & 0,445 & 0,385 & 0,115 & 2,86 \\
\hline
\end{tabular}

The probability of a brittle fracture due to the fragmentation of the compressed sectional area is quite appreciable (more than 10\%) even with reinforcement, which is about $75 \%$ of the boundary value. Moreover, it increases until the exhaustion of the standard resource of frost resistance of concrete. It should be noted that in over-reinforced $\left(\mu \geq \mu_{R}\right)$ elements, there is a significant probability of plastic failure due to the fluidity of the reinforcement. That is, the dual nature of the destruction of reinforced concrete elements in the normal section is possible with a large reinforcement range, which is essential in assessing their reliability.

Numerical modeling of load-carrying capacity of bent elements is performed with the use of the previously presented functional connections (1) and subsequent correction as follows:

$$
M_{p}(m)=\bar{M}(m)-3 \sqrt{D(m)},
$$

where $\bar{M}(m)$ and $D(m)$ are, respectively, the mean value and variance of moments at the considered stage of low-temperature impact. It should be noted that according to [10] the quantities obtained in this case have a security of not less than $99 \%$, regardless of the type and possible transformation of the approximating distribution.

The expected kinetics of the change in the FTC strength of normal cross sections for the range of their actual reinforcement is shown in Figure 1.

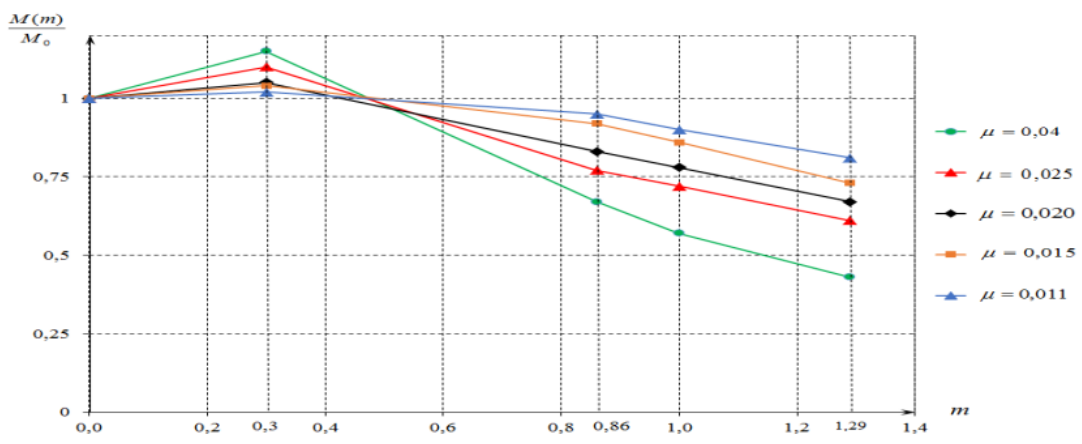

Fig. 1. Relative change in strength of bent elements in FTC.

As should have been expected, there is a period of $(m \leq 0,3 \div 0,4)$ a slight, practically independent of the level $\mu$, increase in the bearing capacity due to the increase in concrete strength with relatively stable variability. In the future, it is most likely to observe its steady decline, the intensity of which essentially depends on the reinforcement and, by the time of exhaustion of the resource of frost resistance of concrete, will reach $10 \div 42 \%$ from the initial (design) value. Such kinetics is preserved in the future $(m>1)$ and is explained by the continuous growth of dispersion of the strength distribution of concrete during its frost destruction [11].

In accordance with the accepted methodology, the safety factor $\gamma_{m}$ defined by function (2) is considered as a monitored index of reliability. The parameters of strength and deformation required for its calculation were taken from the empirical data (Table 1). Other parameters were based on tolerances of the relevant standards. In particular, coefficient of variability in the area of reinforcement was $2.6 \%$. Coefficient of its fluidity index was $5.2 \%$. 
Coefficient of linear dimensions of reinforced concrete elements was $0.5 \%$. At the same time, based on the target tasks of investigating the reliability kinetics in the process of frost destruction, the variability of the parameters of the external impact was not taken into account.

Absolute values of the safety coefficient at different stages of the FTC are given in Table 3 , and its relative change is shown on Figure 2. They confirm the significant and ambiguous effect of the reinforcement level on the reliability index of the bent elements and its kinetics at low-temperature impact. Ambiguity is manifested in the extreme nature of its change with increasing reinforcement, and, in our view, is explained by the limitation of the possibility of realizing the potential of the rebars (achieving fluidity) by the deformative abilities of concrete. In addition, with increasing $\mu$, the probability of brittle failure increases due to premature overcoming of resistance of the compressed zone characterized by a significantly lower density of distribution. Therefore, the extremality of the dependence $\gamma=f(\mu)$ is explained by the objective dual nature of the breaking of the cross sections of bent elements in the range of their reinforcement $\mu=(0,4 \div 1,4) \mu_{R}$.

Table 3. Dynamics of safety coefficient at different stages of FTC.

\begin{tabular}{|c|c|c|c|c|c|c|c|}
\hline $\begin{array}{c}\text { Level of } \\
\text { impact } \\
m\end{array}$ & \multicolumn{7}{|c|}{ Probability value $\gamma$ of reinforced elements with $\mu, \%$} \\
\cline { 2 - 8 } & 1,1 & 1,5 & 2,0 & 2,5 & 3,0 & 3,5 & 4,0 \\
\hline 0 & 4,63 & 5,11 & 5,28 & 6,05 & 5,69 & 5,31 & 5,22 \\
\hline 0,29 & 4,36 & 5,04 & 5,31 & 5,51 & 5,17 & 4,98 & 4,83 \\
\hline 0,86 & 3,17 & 4,01 & 3,72 & 2,92 & 2,66 & 2,17 & 2,03 \\
\hline 1 & 3,14 & 3,76 & 2,81 & 2,65 & 2,35 & 2,21 & 2,12 \\
\hline 1,29 & 3,17 & 3,25 & 2,71 & 2,61 & 2,36 & 2,17 & 2,21 \\
\hline
\end{tabular}

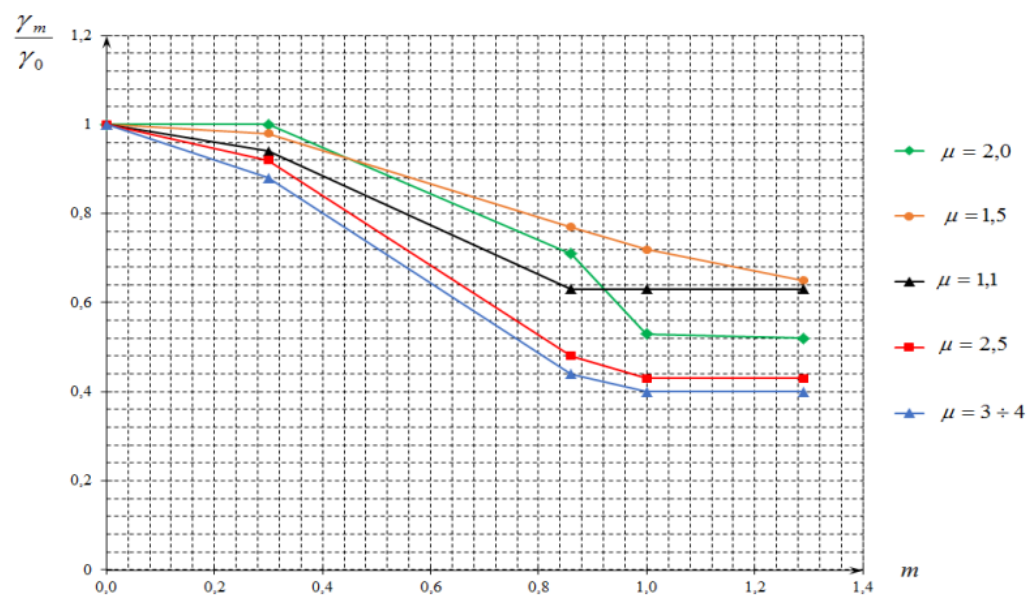

Fig. 2. Relative change of safety coefficient at different stages of FTC.

That is, the risk of parametric failure in the strength of normal sections of bent reinforced concrete elements exceeds the projected expected value.

\section{Conclusion}


1. Bent reinforced concrete elements exposed to cyclic low-temperature and humidity impact are characterized not by the equivalent kinetics of changes in the normative design strength and reliability parameters.

2. On the basis of the effects corresponding to the standard of frost resistance of concrete, the relative decrease in the safety factor is significantly larger and may fall below the minimum acceptable (by the condition of reliability) level.

3. The kinetics of the change in the bearing capacity and reliability essentially depends on the coefficient of reinforcement, which is explained by the dual nature of sections' fracture of bent elements and the gradual increase in the probability of brittle fracture of the compressed part with exhaustion of concrete's frost resistance resource.

4. The acceptable reliability of the bent reinforcement elements for the service life, corresponding to the resource of their frost resistance, can be ensured with reinforcement not exceeding $70 \div 73 \%$ of the boundary value (according to CП63.13330).

\section{References}

1. V. V. Bolotin, Application of methods of probability theory and theory of reliability in the calculation of structures, (Stroiizdat, Moscow, 1971)

2. V. S. Gladkov, Energia, 73L, 133-142 (1972)

3. F. M. Ivanov, Research of frost resistance of concrete, Protection against corrosion of building structures and increase of their durability (Stroyizdat, Moscow, 1969)

4. B. I. Snarsky, Questions of reliability of reinforced concrete structures, 82-86 (1977)

5. N. N. Skladnev, F. E. Dreyer, Construction mechanics and calculation of structures, 5, 3-7 (1983)

6. Yu. A. Sukhov, Construction mechanics and calculation of structures, 4, 13-16 (1974)

7. A. A. Gvozdev, S. A. Dmitriev, S. M. Krylov, New facts about strength of reinforced concrete, (Stroyizdat, Moscow, 1977)

8. A. R. Rzhanitsyn, Theory of calculating building structures for reliability (Stroiizdat, Moscow, 1978)

9. B. I. Pinus, Zh. N. Pinus, I. V. Khomyakova, Vestnik IrSTU, 2, 111-115, (2015)

10. G. Kramer, Mathematical methods of statistics (Mir, Moscow, 1975)

11. E. A. Guzeev, B.I. Pinus, Concrete and reinforced concrete, 10, 9-10 (1984) 